\title{
Wheeze, asthma diagnosis and medication use in developing countries
}

\section{R Becklake}

\section{Sociodemographic, environmental, and medical predictors in a national adult survey conducted in South Africa}

S tandardised population based health surveys have produced much useful information on the prevalence and determinants of asthma in children (International Study of Asthma and Allergy in Children (ISAAC) study) $^{1}$ and adults (European Community Respiratory Health Study (ECRHS) study). ${ }^{2}$ Most sites participating in these studies have been in high income countries and, because some centres took part at their own expense, the populations studied were probably not representative of their countries as a whole. In addition, a number of national health surveys such the US National Health and Nutrition Survey (NHANES), ${ }^{3}$ the Canadian National Health Survey, ${ }^{4}$ and National Birth Cohort Studies (UK, New Zealand) ${ }^{5} 6$ have been conducted, all in high income countries.

In this issue of Thorax Ehrlich et al, ${ }^{7}$ in what is one of the first such studies in a developing (in this case middle income) country, describe the results of a national health survey conducted among 13826 South Africans aged 15 years and over to determine the national prevalence and predictors of three outcomes: (1) wheezing symptoms, (2) an asthma diagnosis, and (3) use of asthma medication. This was an ambitious undertaking (and a remarkably successful one) given the racial, linguistic, and socioeconomic heterogeneity of the population and its quadruple burden of HIV, other infections (including tuberculosis), chronic noncommunicable disease, and injury. What is surprising is not that the findings in this paper ${ }^{7}$ and in its companion paper on chronic bronchitis ${ }^{8}$ were different from those published for developed (high income) countries, but that in how many respects they were similar.

\section{STRENGTHS OF THE STUDY}

Great care was taken by Ehrlich and colleagues to maximise the quality of the data gathered, as evidenced by (1) the use of a national sampling frame (the South African Demographic and
Health Survey) designed to give cross sectional data on a nationally representative sample of the non-institutionalised population; (2) validation of reported recent wheeze against peak expiratory flow (PEF) measurements: in men and women with recent wheeze $\%$ predicted PEF was 4-11\% lower than in those without recent wheeze (see table 1 in their paper ${ }^{7}$ ); (3) although only values for recent wheeze were reported in the paper, its validity was supported by similar findings for three other asthma related symptomswheezing with breathlessness, wheezing not only with a cold, and wheezing at night; (4) the absence of proxy reporting while still achieving a high response rate (92\% in women, $86 \%$ in men); (5) visual verification of current medications by interviewers and their subsequent classification by a health professional; and (6) internal standardisation of PEF values based on sex, age, height and weight (table 1 in their paper ${ }^{7}$ ).

\section{PREVALENCE}

The sex differences in the prevalence of the three main outcomes studied by Ehrlich and colleagues are of interest. For recent wheeze there was an excess in women compared with men (OR 1.6, 95\% CI 1.3 to 1.8); for an asthma diagnosis there was no significant difference (OR 1.2, 95\% CI 0.9 to 1.6); while for current asthma medication use the rates were lower in women than in men (OR 0.6, 95\% CI 0.4 to 0.9) (table 3 in their paper $^{7}$ ). These rates refer to adults aged 15 years and over.

For the purposes of comparison with countries using the ECRHS questions and protocol which covered patients aged 20-44 years, Ehrlich and colleagues $^{7}$ reported separately on subjects within this age range. The prevalence rates of an asthma diagnosis were 3.1\% in women and $2.7 \%$ in men, below the ECRHS median $(4.5 \%)$ and close to its lower range $(2.0 \%) .{ }^{9}$ However, the question used in the study by Ehrlich et al to establish a diagnosis of asthma ("Have you ever been told by a doctor, nurse or other health professional that you have asthma? $?^{\prime \prime 7}$ ) is not the same as the question used in the ECRHS study ("Have you had an attack of asthma in the last 12 months?"'10). Thus, recent wheeze (in the last 12 months) may be a more useful outcome than an asthma diagnosis for comparing the results of the study of Ehrlich and colleagues ${ }^{7}$ with those from high income countries using the ECRHS questions and protocol. Additional justification for use of current wheeze as the outcome is that it has been validated against PEF measurements. This also allowed the authors to avoid use of the term "asthma" in their questionnaire, for which differences in validity were found for some of the ECRHS sites. ${ }^{2} 9$

The prevalence of recent wheeze in the 20-44 year old age range (that is, the ECRHS age range) of $13.4 \%$ in men and women combined was below the ECRHS median (20.7\%). However, when stratified by sex, the prevalence of recent wheeze was higher in women than in men $(17.6 \% \vee 14.4 \%)$. Rates were also higher in women than in men in some low income ECRHS sites-for example, in Mombai (Bombay) in urban India $(4.7 \%$ in women, $4.4 \%$ in men in a study of 2313 adults $^{11}$ ) and in Tirana, Albania $(7.3 \%$ in women, $6.0 \%$ in men in a study of 2653 adults $^{12}$ ). Although recent wheeze was not reported in an analysis of the combined data pertaining to 18659 subjects from 16 high income ECRHS sites in Europe, the US and Australia, ${ }^{13}$ the prevalence of reported asthma was significantly higher in women than in men (RR 1.3-1.8). This pattern was consistent in all 16 countries.

Ehrlich and colleagues speculated that the sex differences in the prevalence of wheeze and reported asthma in their study were artefactual, due to the oversampling of women and/or the undersampling of men away from home at the time of the interviewer's visits. ${ }^{7}$ However, this age range also corresponds to the reproductive period of a woman's life. The fact that the female excess in the prevalence of recent wheeze was strengthened from an OR of $1.3(95 \%$ CI 1.1 to 1.4$)$ in the univariate analysis to an OR of 1.6 (95\% CI 1.3 to 1.8 ) in the logistic regression model, thus adjusting for all the other risk factors studied, suggests that a biological explanation is more likely.

There are recognised sex differences in the morphology and physiology of human airways which affect airway behaviour during a woman's reproductive years. ${ }^{14}{ }^{15}$ These include: (1) dimensional factors: girls and women have larger airways in relation to their airspaces than boys and men throughout 
the human life span; (2) immunological factors: atopy, measured as skin prick test positivity to common allergens, is also higher in women in their reproductive years than in men; and (3) hormonal factors: these are probably the most important determinants of airway behaviour in women throughout their reproductive years, imposing variations related to the menstrual cycle, oral contraceptives, pregnancy, and postmenopausal hormone replacement.

\section{SOCIODEMOGRAPHIC PREDICTORS}

In addition to sex, the sociodemographic predictors of recent wheeze examined in the study by Ehrlich et al included age, household asset index (based on 10 household characteristics such as electricity, water and flush toilets, and reporting that nobody in the household ever went hungry), education, racial group, urban versus rural residence, and medical insurance coverage (table 3 in their paper). For recent wheeze the important predictors were female sex (discussed above), education (a monotonic decrease with increasing years of education), and race (Africans and coloureds exhibited lower rates than whites and Asians).

The protective effect of education for recent wheeze in the study of Ehrlich and colleagues ${ }^{7}$ is a provocative finding. The authors suggest that this effect may be partly explained by cultural and linguistic differences in responses to symptom questions, amplified by a wide gap in education within the study population. However, there is also a plausible alternative explanation.

Although recent wheeze showed a strong inverse relationship with years of education, there was no relationship with wealth as reflected in the asset index, an index carefully constructed to reflect living conditions and household assets. A similar protective effect of years of education, together with wealth (being in the highest quintile of asset index) was also shown for chronic bronchitis in the authors' companion paper to their present study carried out in the same study population, ${ }^{8}$ and in two other studies cited in their paperone for chronic bronchitis in Brazil ${ }^{16}$ and one for obstructive lung disease and spirometric airflow limitation in Norway. ${ }^{17}$ This "protective" effect for different respiratory outcomes in countries with such different economies (the gross domestic product per capita in South Africa, Brazil and Norway was \$8466, \$6477 and \$27 557, respectively $\left.{ }^{18}\right)$, different life expectancies (48.0, 63.2 and 78.9 years, respectively $\left.{ }^{18}\right)$, and different literacy rates $\left(82 \%, 83 \%\right.$ and $100 \%$, respectively $\left.{ }^{18}\right)$ suggests that the "protective" effect of education is a more universal phenomenon than is generally thought.

\section{ENVIRONMENTAL AND MEDICAL PREDICTORS}

In their study, Ehrlich et al identified occupational exposure and, to their surprise, a past history of tuberculosis as predictors for recent wheeze (table 3 of their paper). The estimated contributions of occupational exposure, expressed as population attributable fraction) for recent wheeze and for asthma were $12.2 \%$ and $13.6 \%$, respectively, close to the median estimate of $15 \%$ for asthma published in a recent American Thoracic Society statement based on a review of European and US data. ${ }^{19}$

Although Ehrlich and colleagues note that the PAF of $12.2 \%$ for occupational exposure in respect of recent wheeze approximates that of light and heavy smoking combined (11.5\%), they do not comment specifically on the role of smoking. Others have called cigarette smoking and asthma "a dangerous mix". ${ }^{20}$ These authors draw attention to the fact that, in Canada for instance, smoking is as common in those suffering from asthma as it is in the general population, including the 20-35 year age group. Active smoking is also associated with increased asthma morbidity and impairment of the response to steroids, leading the authors to call for a reassessment of guidelines for asthma treatment. ${ }^{20}$

In their national survey, Ehrlich and colleagues $^{7}$ captured what had already been described in black gold miners ${ }^{21}$ (that tuberculosis can cause chronic impairment of lung function) and what was subsequently described in black coal miners ${ }^{22}$ in whom a past history of tuberculosis accounted for reductions in the level of $\mathrm{FEV}_{1}$ and $\mathrm{FVC} \%$ predicted of $20 \%$ and $14 \%$, respectively. They also advocate for greater recognition of posttuberculous obstructive lung disease. This implies that the clinical history of the adult South African who wheezes should always include detailed questioning on past exposure to tuberculosis, tuberculin testing, and BCG administration as well as having contracted the disease. Their message may be relevant for other countries with high rates of tuberculosis, HIV/AIDS, or both. Their recommendation for increased future research into the mechanisms certainly deserves widespread support.

\section{CONCLUSIONS}

In addition to establishing the national prevalence of wheeze, an asthma diagnosis and asthma medication use in South Africa, the study by Ehrlich and colleagues has led to four interesting observations:

- For the outcome "current wheeze", the most important determinants in adults aged 15 years and older (expressed as population attributable fraction \%) were occupational exposure $(12.2 \%)$, light $(7.8 \%)$ and heavy smoking $(3.7 \%)$, tuberculosis ever $(5.4 \%)$, and obesity (3.8\%). All were significant except obesity.

- Sex differences in the prevalence of asthma (higher rates in women in their reproductive years than in men) were confirmed in the South African population. They are most unlikely to be artefactual.

- Control of hazardous occupational exposure merits equal attention to the more visible tobacco control activities in the public health institutes in South Africa. The authors also make the case for greater clinical recognition of post-tuberculous obstructive lung disease. These conclusions may be applicable to other populations in high as well as in low and middle income countries.

- In South Africa (which Erlich et al characterise as a medium income country but with large scale urban poverty and rural underdevelopment), education was protective for the outcome "recent wheeze", a relationship not accounted for by a marker of "worldly wealth" in the form of the carefully constructed asset index developed for the national health survey. This was a consistent finding for which the reasons and/or mechanisms are not obvious and one which invites further investigation.

\section{ACKNOWLEDGEMENTS}

I am grateful for comments and advice from Professors Maurice McGregor and Richard Menzies, McGill University.

Thorax 2005;60:885-887.

doi: $10.1136 /$ thx.2004.035980

Correspondence to: Professor M R Becklake, Respiratory Epidemiology and Clinical Research Unit, Montréal Chest Institute, $3650 \mathrm{St}$ Urbain Street, Montréal, Québec, Canada H2X 2P4; margaret.becklake@mcgill.ca

\section{REFERENCES}

1 Asher MI, Keil U, Anderson HR, Beasley R. et al International Study of Asthma and Allergies in Childhood (ISAAC): rationale and methods. Eur Respir J 1995;8:483-91.

2 Burney P, Lukzynska C, Chinn S, et al. The European Community Respiratory Health Survey (ECRHS). Eur Respir J 1994;7:954-60.

3 National Center for Health Statistics (NCHS). Plan and operation of the Third National Health and Nutrition Survey, 1988-1994, DHHS Publication No (PHS) 94-1302. Washington, DC: US Government Printing Office, 1994. 
4 Chen $Y$, Dales R, Tang $M$, et al. Obesity may increase the incidence of asthma in women bu not men: longitudinal observations from the Canadian National Population Health Surveys. Am J Epidemiol 2002;155:191-7.

5 Shaheen SO, Sterne JAC, Montgomery SM, et al. Birth weight, body mass index and asthma in young adults. Thorax 1999;54:396-402.

6 Sears MR, Holdaway MD, Plannery EM, et al. Parental and neonatal risk factors for atopy, airway hyper-responsiveness and asthma. Arch Dis Child 1996;75:392-8.

7 Ehrlich RI, White N, Norman R, et al. Wheeze, asthma diagnosis and medication use: a national adult survey in a developing country. Thorax 2005;60:895-901.

8 Ehrlich RI, White N, Norman R, et al. Predictors of chronic bronchitis in South African adults. Int J Tuberc Lung Dis 2004;8:369-78.

9 Janson C, Anto J, Burney P, et al. The European Community Health Survey: what are the main results so far? Eur Respir J 2001;18:596-611.

10 Burney $\mathbf{P}$, Chinn S, Jarvis D, et al. Variations in the prevalence of respiratory symptoms, selfreported asthma attacks, and the use of asthma medication in the European Community
Respiratory Health Study (ECRHS). Eur Respir $J$ 1996;9:687-95.

11 Chowgule RV, Setye VS, Parmar JR, et al. Prevalence of respiratory symptoms, bronchial hyperreactivity, and asthma in a megacity (Bombay). Am J Respir Crit Care Med 1998; 158:547-54.

12 Priftanji AV, Qirko E, Layzell JCM, et al. Asthma and allergy in Albania. Allergy 1999:54:1042-7.

13 de Marco R, Locatelli F, Sunyer J, et al. Differences in incidence of reported asthma related to age in men and women. Am J Respir Care Crit Med 2000:162:68-74.

14 Kauffmann F, Becklake MR. Les maladies obstructives pulmonaires: un paradigme de la complexité des différences entre femmes et hommes. In:Saurel-Cubizolles MJ, Blondel B, éds. La santé des femmes. Paris: Medicine-Flammarion, 1996:209-33.

15 Becklake MR, Kauffmann F. Gender differences in airway behaviour across the human lifespan. Thorax 1999:54:1119-38.

16 Menezes AMB, Victoria CG, Rigatto M. Prevalence and risk factors for chronic bronchitis in Pelotas, RS, Brazil: a population based study Thorax 1994;49:1217-21.

17 Bakke P, Hanoa R, Gulsvik A. Educational level and obstructive lung disease given smoking habits and occupational airborne exposure: a Norwegian community study. Am J Epidemiol 1995; 141:1080-8.

18 CIA World Fact Book July 1, 2002. http. www.mrdowling.com

19 Balmes J, Becklake $M$, Blanc $P$, et al Occupational contribution to the burden of airway disease. American Thoracic Society Statement. Am J Respir Crit Care Med 2003;167:787-97.

20 Lemeire C, Boulet L-P. Cigarette smoking and asthma: a dangerous mix. Can Respir $J$ 2005; 12:79-80.

21 Hnizdo E, Singh T, Churchyard GJ. Chronic pulmonary function impairment caused by initial and recurrent pulmonary tuberculosis treatment. Thorax 2000;55:32-8

22 Naidoo RN, Robins TG, Seixas N, et al. Differential respirable dust related lung function effects between current and former South African coal miners. Int Arch Occup Environ Health 2005;78:293-302

\section{Exercise in COPD: damned if you do and damned if you don't}

\section{P T Macklem}

\section{Recruitment of the expiratory muscles by COPD patients during exercise}

n this issue of Thorax Aliverti et al present the most complete description of the effect of bronchodilators in chronic obstructive pulmonary disease (COPD) to date. Surprisingly, they found that the patient population separated cleanly into two groups: those whose exercise endurance was improved and those whose exercise endurance decreased. This unexpected adverse effect was not trivial: endurance time at constant workload decreased on average by $34 \%$, while endurance time in those who improved increased by $86 \%$. They called this group the "improvers", and those whose exercise performance became worse the "nonimprovers"; a more accurate moniker for the non-improvers would be "worseners". Both groups dynamically hyperinflated to the same extent during exercise after placebo, whereas following bronchodilation the improvers hyperinflated more than the worseners so that, at the limit of endurance, inspiratory reserve volume was considerably larger in the latter.

In a previous paper Aliverti et al studied patients with stable COPD during incremental exercise and found that
$60 \%$ dynamically hyperinflated while $40 \%$ did not. The latter group (which they called "euvolumics") decreased end expiratory volume during exercise, just as healthy subjects do. The euvolumics had significantly better resting lung function but, paradoxically, significantly worse exercise performance.

The implication of these two papers is that, in COPD, it is better to hyperinflate dynamically because it improves exercise performance than to use a breathing pattern which mimics that used by healthy subjects. What on earth is going on here? According to many experts, dynamic hyperinflation is supposed to be the most important factor limiting exercise in COPD.

In a study of 105 patients with COPD, O'Donnell et $a l^{3}$ found dynamic hyperinflation occurred in $80 \%$ of patients during incremental exercise. These researchers measured inspiratory capacity by integrating flow at the mouth as an index of hyperinflation and found that it decreased by a mean (SD) of $0.37(0.39) \mathrm{l}$. On the other hand, Aliverti et al measured chest wall volumes by optoelectronic plethysmography (OEP). Could the difference between the methods of measurement have led to an underestimation of dynamic hyperinflation by OEP and/or an overestimation by spirometry?

Spirometry measures the volume of gas entering or leaving the lungs at the mouth. OEP measures the volume of the trunk. This includes volume changes at the mouth, but also two other variables-gas compression and decompression in the lungs, and blood shifts between the trunk and extremities. In normal subjects exercising with a Starling resistor in the expiratory line to limit expiratory flow to approximately $1 \mathrm{l} / \mathrm{s}$, gas compression due to expiratory muscle recruitment and blood shifts can be substantial. ${ }^{4}$ On average, normal subjects shift $7.2 \mathrm{ml}$ blood from the trunk to the extremities for every $1 \mathrm{~cm} \mathrm{H}_{2} \mathrm{O}$ increase in alveolar pressure. The euvolumics in Aliverti's first study ${ }^{2}$ generated peak expiratory pleural pressures of about $22 \mathrm{~cm} \mathrm{H}_{2} \mathrm{O}$ at maximal exercise workload. Peak alveolar pressures would be higher by an amount equal to the elastic recoil pressure of the lung. Assuming that (1) peak alveolar pressures were $25 \mathrm{~cm} \mathrm{H}_{2} \mathrm{O}$, (2) blood shifts were $7.2 \mathrm{ml} / \mathrm{cm} \mathrm{H}_{2} \mathrm{O}$, and (3) the operating lung volumes were 6 litres, OEP would measure a minimal expiratory chest wall volume that would be $330 \mathrm{ml}$ less than the minimal lung volume measured by spirometry. Thus, OEP would not detect $89 \%$ of the reduction in inspiratory capacity measured by O'Donnell and colleagues.

However, if this were the case, minimal chest wall volume would occur during expiration and not at end expiration. This has been shown in normal subjects exercising with expiratory flow limitation. ${ }^{4}$ During control exercise, 
volume changes measured by spirometry and OEP went along the line of identity whereas, with flow limitation, expiratory chest wall volume led the spirometric volume in time and magnitude and reached a minimum before expiratory flow at the mouth ceased. Dynamic hyperinflation as assessed by OEP must be done at zero flow points, not at minimal chest wall volume. It is unclear which volume was chosen by Aliverti et al. ${ }^{12}$

It would be better to make the comparison between OEP and spirometry at end inspiration. Certainly there would be no gas compression at this point, although it is doubtful whetherwith inspiration taking less than 2 seconds-there would be sufficient time for blood to shift back from the extremities to the trunk. The difference in end inspiratory volumes between improvers and worseners just before stopping exercise was about $400 \mathrm{ml}$, a little large to be accounted for by blood shifts alone. Nevertheless, euvolumics measured by OEP might well be called "hyperinflators" if measured by spirometry.

But it seems clear that there are euvolumics measured by spirometry. O'Donnell's data ${ }^{3}$ revealed a decrease in mean (SD) inspiratory capacity of 370 (390) $\mathrm{ml}$. Assuming these data to be normally distributed, one would expect to see changes in end expiratory lung volume ranging from an increase of $+1150 \mathrm{ml}($ mean $+2 \mathrm{SD})$ to a decrease of $-410 \mathrm{ml}$ (mean - 2SD). The decrease is virtually identical to the mean value measured by Aliverti et al in the euvolumics. ${ }^{2}$ What remains unclear is the percentage of patients with COPD who are euvolumics or hyperinflators.

Is it relevant to know this percentage? I doubt it. The essential difference between improvers and worseners ${ }^{1}$ and between euvolumics and hyperinflators ${ }^{2}$ was not so much about what happened to their lung volumes, but the degree of expiratory muscle recruitment. The kinematic difference between improvers and worseners was in the behaviour of the abdomen. After bronchodilators there was inward abdominal displacement at end expiration to a volume considerably less than that during quiet breathing in the worseners, but no change from quiet breathing in the improvers. The worseners were using the abdomen to pump the lungs much more than the improvers. This requires coordinated activity of the abdominal muscles and the diaphragm so that, as the diaphragm contracts during inspiration the abdominal muscles relax, and vice versa during expiration. ${ }^{5}$ This is the normal response to exercise and it requires a simple respiratory muscle neural control system by which the rib cage muscles and the abdominal muscles are activated $180^{\circ}$ out of phase with each other. ${ }^{5}$ This neural control mechanism is not used at rest but is brought into play as soon as exercise starts, even at minimal workloads. It is as if a switch occurred in the central neural drive to breathe to recruit expiratory muscles immediately at the onset of exercise. This is what happened in the euvolumics and worseners so the neural drive to their respiratory muscles was "normal". This is hardly surprising.

The problem is that, in COPD, the expiratory flow generated by the abdominal pump becomes limited by dynamic airway compression. Thus, the power output of the abdominal muscles (the product of their velocity of shortening and the force they develop) is expressed more as pressure and less as flow. This was first recognised by Potter et $a l^{6} 34$ years ago. They observed that, during exercise, some patients with COPD were euvolumics and that excessive expiratory muscle recruitment occurred. They questioned whether or not the high expiratory pressures had adverse circulatory effects. It is now known that expiratory muscle recruitment during flow limited exercise acts as a Valsalva manoeuvre, decreasing cardiac output and producing the blood shifts from trunk to extremities. ${ }^{4} 7$ In addition, the oxygen cost of breathing is so high in COPD that it can become a very large percentage of total body oxygen uptake. ${ }^{8}$ This can establish competition between respiratory and locomotor muscles for the available oxygen supply ${ }^{10}$ at low exercise workloads. ${ }^{10}$ It seems that the combination of high ventilatory oxygen demands and limitation of cardiac output-both caused by excessive expiratory pressures-can be a potent factor limiting exercise performance in COPD.

This raises the question whether exercise might be improved if appropriate physiotherapy programmes could train patients to relax their expiratory muscles. The benefits could be substantial: there would be a reduction in the oxygen cost of breathing and the cardiac output should increase, and the competition between respiratory and locomotor muscles would be alleviated. This would require an "abnormal" response to exercise so that the abdominal pump would be activated to a much lesser degree. Although this may be an interesting question, I think we already have the answer. This is what the improvers and the hyperinflators do. ${ }^{12}$ Their expiratory muscle recruitment, work of breathing, and competition between respiratory and locomotor muscles are all considerably less than in euvolumics and worseners. ${ }^{2}{ }^{10}$ They have learned to bypass the normal control of the respiratory muscles and, hence, their expiratory pressures remain low. Even if expiratory pressures are substantial, dynamic hyperinflation appears to minimise its effect on cardiac output. ${ }^{11}$ Are they improved as a result? Not much.

Without expiratory muscle recruitment, dynamic hyperinflation is inevitable if patients are sufficiently flow limited. There can be no doubt that dynamic hyperinflation is a common and potent mechanism limiting exercise in COPD. A great deal of research has shown that patients are crippled as a result. Recruit your expiratory muscles or not, patients with COPD are damned if they do and damned if they don't. Nevertheless, dynamic hyperinflation does seem to be a better strategy for exercise in COPD than the one adopted by healthy subjects and worseners. But it does not confer much benefit.

Thorax 2005;60:887-888.

doi: $10.1136 /$ thx. 2005.042473

Correspondence to: Professor P T Macklem, Meakins Christie Laboratories, Montreal Chest Institute, McGill University Health Centre Research Institute, P O Box 250, Lansdowne ON, Canada KOE 1LO; ptm01@hotmail.com

\section{REFERENCES}

1 Aliverti A, Rodger K, Dellacà RL, et al. Effect of salbutamol on lung function and chest wall volumes at rest and during exercise in COPD. Thorax 2005:60:916-24.

2 Aliverti A, Stevenson N, Dellacà RL, et al. Regional chest wall volumes during exercise in chronic obstructive pulmonary disease. Thorax 2004;59:210-6.

3 O'Donnell DE, Revill SM, Webb KA. Dynamic hyperinflation and exercise intolerance in chronic obstructive pulmonary disease. Am J Respir Crit Care Med 2001;164:770-7.

4 landelli I, Aliverti A, Kayser B, et al. Determinants of exercise performance in normal men with externally imposed expiratory flow limitation. J Appl Physiol 2002;92:1943-52.

5 Aliverti A, Cala SJ, Duranti R, et al. Human respiratory muscle actions and control during exercise. J Appl Physiol 1997:83:1256-69.

6 Potter WA, Olafsson S, Hyatt RE. Ventilatory mechanics and expiratory flow limitation during exercise in patients with obstructive lung disease. J Clin Invest 1971;50:910-9.

7 Aliverti A, Dellacà RL, Lotti $P$, et al. Influence of expiratory flow-limitation during exercise on systemic oxygen delivery in humans. Eur J Appl Physiol 2005 (in press)

8 Levison $\mathrm{H}$, Cherniack RM. Ventilatory cost of exercise in chronic obstructive pulmonary disease. J Appl Physiol 1968;25:21-7.

9 Roussos C, Macklem PT. The respiratory muscles. N Engl J Med 1982;307:786-97.

10 Macklem PT. Competition between respiratory and locomotor muscles for available energy supplies during exercise in COPD. Proc Am Thorac Soc 2005;2:A304.

11 Stark-Leyva KN, Beck KC, Johnson BD. Influence of expiratory loading and hyperinflation on cardiac output during exercise. J Appl Physiol 2004;96:1920-7. 


\section{Exercise training and inspiratory muscle training in patients with bronchiectasis}

\section{R S Goldstein}

\section{Evidence for effectiveness of pulmonary rehabilitation in patients with bronchiectasis}

$\mathrm{P}$ ulmonary rehabilitation is now recommended by many professional respiratory societies as the standard of care for patients with chronic lung disease. ${ }^{1-3}$ This has occurred because well designed prospective randomised controlled trials using valid responsive and interpretable outcome measures have convinced clinicians of its effectiveness. Benefits of pulmonary rehabilitation include improved health related quality of life, increased functional exercise capacity, and reduced healthcare resource utilisation. ${ }^{4-6}$ The key determinant of the success of rehabilitation, and the one best supported by clinical evidence, is exercise training.

A frequently encountered challenge in respiratory medicine is that of extending the clinical application of treatment modalities, for which evidence was derived from one clinical circumstance, to other circumstances or diagnostic categories. For example, we recognise that long term oxygen therapy is life extending for patients with stable severe chronic obstructive pulmonary disease (COPD) who have resting hypoxaemia, but still wrestle with the challenge of whether it should be provided for those with transient exercise or sleep hypoxaemia, or those with other diagnoses not involved in landmark multicentre clinical trials. Such decisions are made using a combination of scientific evidence and clinical judgement, the latter being a less well defined entity that includes knowledge, experience, and common sense.

The paper by Newall and colleagues ${ }^{7}$ in this issue of Thorax obliges us to consider the evidence in favour of extending pulmonary rehabilitation to patients with bronchiectasis, a chronic suppurative lung disease often characterised by airflow obstruction and hyperinflation and associated with decreased health related quality of life and reduced functional exercise capacity. Two issues arise: (1) does a prescribed regimen of physical training produce improvements in physiological or clinical outcomes compared with no physical training, and (2) should such a programme include inspiratory muscle training (IMT)?

There are marked similarities in the disease manifestations of COPD and bronchiectasis, both having a primary pulmonary impairment and both having secondary peripheral muscle, nutritional and psychological impairments. Given the similarities in clinical outcomes of reduced ability and participation, it is not too far of a stretch to conclude that both conditions might benefit from an exercise rehabilitation programme.

In 1990 Foster and colleagues ${ }^{8}$ published a report on pulmonary rehabilitation in lung diseases other than COPD in which seven patients with bronchiectasis were included in the 32 patients enrolled in an inpatient programme. The 6 minute walk distance in patients with bronchiectasis improved by approxiable to that achieved by patients with COPD. Despite the small number of patients studied, the authors concluded that patients with diagnoses other than COPD can and do benefit from an inpatient multidisciplinary rehabilitation programme. In 2002 Bradley and colleagues $^{9}$ undertook a systematic review of physical training for bronchiectasis in which they wished to determine whether exercise training improved or prevented deterioration in physiological and clinical outcomes compared with no exercise. They identified three studies, one of which did not meet the inclusion criteria and two of which were in abstract form (both by the current author). Bradley concluded that there was a need for well designed, adequately powered, randomised controlled clinical trials to assess the net benefit of adherence to different forms of prescribed physical training in patients with bronchiectasis.

The study by Newall et al is therefore welcomed as one of only a few published trials in this area. They mately 72 metres, a distance compar- randomised 32 patients with idiopathic bronchiectasis into one of three groups: pulmonary rehabilitation plus inspiratory muscle training (PR-IMT), pulmonary rehabilitation plus sham IMT (PRSHAM), and a control group. The rehabilitation patients all underwent 8 weeks of exercise training, attending for supervised outpatient sessions twice a week with a third session at home. Patients exercised for 45 minutes at $80 \%$ peak heart rate using a combination of cycle, treadmill, and stair climbing exercises.

The 23 patients randomised to exercise rehabilitation improved their constant power exercise endurance, measured using a treadmill, as well as their incremental shuttle walk test. No differences in peak oxygen uptake occurred, but there were significant increases in endurance exercise capacity, the magnitude of which was similar in the groups whose regimen included IMT and sham IMT. It would therefore appear that the first question has been answered, albeit in a small pilot sized trial-namely, that exercise training improves exercise capacity in patients with bronchiectasis.

The second question may be slightly more problematic depending on one's view of the merits of IMT, about which a great deal has been written since it was first seriously considered as a clinical modality in the 1980s. Although it has been suggested that IMT may be an important adjunct to pulmonary rehabilitation, many clinicians have refrained from including it in their rehabilitation programme as clinical trials and meta-analyses still differ on whether a modest improvement in inspiratory muscle pressure can be translated into meaningful clinical improvements. ${ }^{10-13}$ Respiratory muscles are autotrained against the increased respiratory obstructive and elastic loads associated with airflow limitation and hyperinflation, respectively. It has been shown that training using alinear resistors, pressure threshold loads, or isocapnic hyperpnoea will improve test function, but it is necessary for such training to extend the impact on clinical outcomes beyond exercise alone for it to be routinely included. ${ }^{14}$ There is evidence that IMT improves inspiratory muscle strength, dyspnoea, and exercise tolerance, ${ }^{15}$ but these effects are more likely to be obvious in patients with markedly reducted inspiratory muscle strength.

In the study by Newall et al, both the PR-IMT and the PR-SHAM groups had small but similar improvements in respiratory muscle strength. The addition of IMT did not add to outcomes beyond this increase. It could be argued 
that small sample size and only a modest baseline reduction of inspiratory muscle strength prevented a more conclusive answer but, as with COPD, many clinicians will regard these data as insufficient to warrant using IMT for patients with bronchiectasis. Indeed, a recent meta-analysis of IMT for patients with COPD by Geddes and colleagues ${ }^{16}$ concluded that it was only effective when using targeted devices that control or provide a target for training intensity.

There are several unanswered issues regarding training for patients with bronchiectasis which mirror the challenges of training for patients with COPD. The intensity, frequency, and duration of training, as well as the optimal strategy for maintenance of benefit, are common to both conditions. Additional issues specific to rehabilitation of patients with bronchiectasis include the optimal approaches for secretion clearance and specific education self-management action plans. Such issues should attract further well designed trials among this population. Bronchiectasis is no longer as common a condition as it used to be, but it is still present and many clinicians will continue to enrol patients with bronchiectasis in pulmonary rehabilitation, modifying the programme to help them tackle the issues specific to their condition. We will also continue to do so, but with slightly more comfort following the evidence of effectiveness described by Newall and colleagues.

Thorax 2005;60:889-890.

doi: $10.1136 /$ thx.2005.043810

Correspondence to: $\operatorname{Dr} R$ S Goldstein, Professor of Medicine and Physical Therapy, University of Toronto, West Park Healthcare Centre, 82 Buttonwood Avenue, Toronto, Ontario, M6M 2J5 Canada; rgoldstein@westpark.org

\section{REFERENCES}

1 O'Donnell DE, Aaron S, Bourbeau J, et al. State of the Art Compendium: Canadian Thoracic Society recommendations for the management of chronic obstructive pulmonary disease. Can Respir J 2004; 11(Suppl B):7B-59B.

2 COPD Guidelines Group of the Standards of Care Committee of the BTS. BTS guidelines for the management of chronic obstructive pulmonary disease. Thorax 1997;52(Suppl 5).

3 European Respiratory Society. Consensus statement: Optimal assessment and management of chronic obstructive pulmonary disease (COPD). Eur Respir J 1995;8:1398-420.

4 Lacasse Y, Wong E, Guyatt GH, et al. Metaanalysis of respiratory rehabilitation in chronic obstructive pulmonary disease. Lancet 1996:348: 1115-9.

5 Griffiths TL, Burr ML, Campbell IA, et al. Results at 1 year of outpatient multidisciplinary pulmonary rehabilitation: a randomised controlled trial. Lancet 2000:355:362-8.

6 Bourbeau J, Julien M, Maltais F, et al. Reduction of hospital utilization in patients with chronic obstructive pulmonary disease: a disease-specific self-management intervention. Arch Intern Med 2003; 163:585-91

7 Newall C, Stockley RA, Hill SL. Exercise training and inspiratory muscle training in patients with bronchiectasis. Thorax 2005;60:943-8.

8 Foster S, Thomas HM. Pulmonary rehabilitation in lung disease other than chronic obstructive pulmonary disease. Am Rev Respir Dis 1990;141:601-4.

9 Bradley J, Moran F, Greenstone M. Physical training for bronchiectasis (Cochrane Review). In: The Cochrane Library, Issue 1. Oxford: Update Software, 2003.

10 Smith K, Cook D, Guyatt GH, et al. Respiratory muscle training, chronic airflow limitation: a meta analysis. Am Rev Respir Dis 1992; 145:533-9.

11 Lotters F, Van Tol B, Kwakkel G, et al. Effects of controlled inspiratory muscle training in patients with COPD: a meta analysis. Eur Respir J 2002;20:570-6

12 Lacasse Y, Guyatt GH, Goldstein RS. The components of respiratory rehabilitation programme. A systematic overview. Chest 1997; $111: 1077-88$.

13 Weiner P, Magadle R, Beckham W, et al. Maintenance of inspiratory muscle training in COPD patients: 1 year follow-up. Eur Respir $J$ 2004;23:61-5.

14 Polkey MI, Moxham J. Improvement in volitional tests of muscle function alone might not be adequate evidence that inspiratory muscle training is effective. Eur Respir J 2004; 23:5-6.

15 Harver A, Mahler DA, Daubenspck JA. Target inspiratory muscle training improve respiratory muscle function and reduces dyspnea in patients with chronic obstructive pulmonary disease. Ann Intern Med 1989;111:1171.

16 Geddes EL, Reid WD, Crowe J, et al. Inspiratory muscle training in adults with chronic obstructive pulmonary disease: a systematic review. Respir Med 2005 (in press).

\section{Usefulness of transbronchial needle aspiration in evaluating patients with lung cancer}

\section{S Gasparini, G A Silvestri}

\section{There is a need to promote more widespread use of TBNA for evaluating NSCLC}

S ince the introduction of flexible bronchoscopes in 1968, ${ }^{1}$ various ancillary related methods of sampling lung tissue have been developed to greatly expand the diagnostic capabilities of the procedure. Perhaps the most important innovation has been the development of needles with the ability to puncture the tracheobronchial wall, allowing the bronchoscopist to go beyond the barrier of the airways to obtain specimens from both hilar and mediastinal structures.

After the publication of Dr KoPen Wang's initial experience with transbronchial needle aspiration (TBNA) in the $1980 \mathrm{~s}^{23}$ it became clear that this technique had great potential in both the diagnosis and staging of lung cancer as well as other diseases. The only limiting requirement is that the lymph node must be in close contact with the airways, which is most frequently the case in patients with lung cancer. Despite numerous publications highlighting the safety and accuracy of this procedure, the technique is still underused by pulmonologists. Based on data compiled from Europe and the United States, it has been estimated that the percentage of pulmonologists using TBNA is between $11 \%$ and $30 \%$. $^{4-6}$

The three most often cited reasons for not performing TBNA are: (1) problems with the technique $(30 \%)$; (2) a belief that TBNA is not useful (30\%); and (3) the lack of on-site cytopathology to assess the adequacy of the specimen $(14 \%) .^{7}$

The belief that TBNA is not useful deserves further exploration. There appears to be confusion in the literature regarding the diagnostic accuracy of this procedure. There is uniform agreement that the specificity is high (approaching $100 \%$ ) with very few false positives. However, the sensitivity varies greatly in the literature and is influenced by factors such as the size and location of the lymph nodes, ${ }^{8}$ the type of needle used, ${ }^{10}$ the number of aspirates performed, ${ }^{11}$ the nature of the lesion, ${ }^{12}$ the availability of immediate cytological assessment, $^{13}$ and the means of guidance. $^{14}$ The sensitivity of TBNA also depends on the skill of the operator, and even experienced bronchoscopists may be frustrated by discouraging results during their first attempts with TBNA where performance requires some technical knowledge that is not intuitive. Several studies have shown that the 
sensitivity of the technique may improve greatly with training. ${ }^{15-17}$ Another factor in evaluating the sensitivity of TBNA is that some studies do not verify negative results by the gold standard (mediastinoscopy), making it difficult to identify the true incidence of true and false negatives. In fact, sensitivity is sometimes reported as a range varying from the worst case scenario (all the negative TBNA results are considered as false negatives) to the best case scenario (all the negative TBNA results are considered as true negatives). ${ }^{8}$

In this context the meta-analysis by Holty and colleagues published in this issue of Thorax makes a considerable contribution to the clarification of this subject by estimating the diagnostic accuracy of TBNA in the staging of patients with non-small cell lung cancer (NSCLC). ${ }^{18}$ The authors examined the results of 13 studies (selected out of 67; 54 studies were excluded because they provided insufficient data to calculate sensitivity or specificity or enrolled fewer than $90 \%$ of subjects with NSCLC). The results of this analysis confirm the safety of TBNA ( $0.3 \%$ major complication rate) and the high specificity of this technique (99\%: only four false positive results in the eight studies that surgically confirmed all TBNA results). Conversely, Holty et al ${ }^{18}$ were not able to confirm the high sensitivity of $76 \%$ reported in a previous recent meta-analysis, ${ }^{19}$ identifying the prevalence of mediastinal lymph node metastases as a source of variability. When considering the five more methodologically rigorous studies in which the prevalence of lymph node metastases was low (34\%), the pooled sensitivity was surprisingly poor $(39 \%)$, while in the eight studies that used suboptimal methodological criteria and in which the prevalence of mediastinal metastases was $81 \%$, TBNA sensitivity was $78 \%$. The conclusions of Holty et al are that the accuracy of TBNA depends critically on the prevalence of mediastinal lymph node involvement and that, in the patient population with a low prevalence of mediastinal disease (patients who could benefit from surgery), the sensitivity of the technique is really poor.

Should these conclusions diminish the value of TBNA in the staging of NSCLC and discourage bronchoscopists from using this technique more extensively? We do not think so. The algorithm for evaluating a patient with suspected lung cancer should include a chest CT scan at the outset to evaluate the size and location of the mass and the presence of adenopathy. If the patient has enlarged mediastinal lymph nodes in areas accessible by TBNA, a bronchoscopic examination should be performed guided by the CT findings. In this setting, TBNA can provide both the diagnosis and stage simultaneously in a minimally invasive setting, thus obviating the need for any further invasive investigations. The sensitivity should be high because the prevalence of mediastinal lymph node involvement can be expected to be high based on the CT findings. This meta-analysis makes that point painstakingly clear. Still, even if the sensitivity were as low as $40 \%$, we believe TBNA would be worthwhile as it would avoid further invasive testing in $40 \%$ of patients. It should also be noted that this technique has been the only method to yield a diagnosis in $18-38 \%$ of patients ${ }^{78}$ in whom lung cancer presented without endobronchial involvement.

Pulmonologists should read carefully the work of Holty et al, even to improve their methodology for conducting studies on TBNA. It is surprising that, as reported by the authors, $76 \%$ of the published papers on TBNA were excluded from this meta-analysis because they provided insufficient data to calculate sensitivity or specificity! Future work on this technique should use more rigorous methodological criteria to satisfy the quality level required to evaluate precisely the diagnostic accuracy of TBNA.

Clinicians who are already performing TBNA must continue to make every effort to improve their skills and diagnostic accuracy. We are encouraged by a recent survey that showed that $90 \%$ of trainees in US pulmonary fellowship training programs are learning TBNA and $60 \%$ are reaching competency numbers set out by the American College of Chest Physicians. ${ }^{20}{ }^{21}$ Those who are not yet performing this technique should consider acquiring the necessary skills to perform the procedure and then practise, practise and practise: results will come. Performing TBNA during the initial bronchoscopic examination when there is an indication will optimise the care of the patient with lung cancer.

Thorax 2005;60:890-891. doi: 10.1136/thx.2005.048728

\section{Authors' affiliations}

S Gasparini, Pulmonary Diseases Unit, Azienda Ospedaliero-Universitaria Ospedali Riuniti, Ancona, Italy G A Silvestri, Medical University of South Carolina, Charleston, SC, USA
Correspondence to: Dr S Gasparini, U.O. Pneumologia, Azienda OspedalieroUniversitaria Ospedali Riuniti, Via Conca, Ancona 60020, Italy; s.gasparini@fastnet.it

\section{REFERENCES}

1 Ikeda S, Yanai N, Ishikawa S. Flexible bronchofiberscope. Keio J Med 1968;17:1

2 Wang KP, Brower R, Haponik EF, et al. Flexible transbronchial needle aspiration for staging of bronchogenic carcinoma. Chest 1983;84:571-6.

3 Wang KP, Terry PB. Transbronchial needle aspiration in the diagnosis and staging of bronchogenic carcinoma. Am Rev Respir Dis 1983;127:344-7.

4 Gasparini S. Transbronchial needle aspiration: the European experience (abstract). Tenth International Course of Interventional Bronchoscopy, Barcelona, April, 2002.

5 Haponik E, Russell G, Beamis J, et al. Bronchoscopic training: current fellows' experiences and some concerns for the future. Chest 2000;118:625-30.

6 Smyth CM, Stead RJ. Survey of flexible fiberoptic bronchoscopy in the United Kingdom. Eur Respir J 2002; 19:458-63.

7 Haponik EF, Shure D. Underutilization of transbronchial needle aspiration. Chest 1997; 1 12:251-3.

8 Patelli M, Lazzari Agli L, Poletti V, et al. Role of fiberscopic transbronchial needle aspiration in the staging of N2 disease due to non-small cell lung cancer. Ann Thorac Surg 2002;73:407-1 1 .

9 Harrow EM, Abi-Saleh W, Blum J, et al. The utility of transbronchial needle aspiration in the staging of bronchogenic carcinoma. Am J Respir Crit Care Med 2000;161:601-7.

10 Schenk DA, Chambers SL, Derdak S, et al. Comparison of the Wang 19-gauge and 22gauge needles in the mediastinal staging of lung

11 Chin R Jr, McCain TW, Lucia MA, et al. Transbronchial needle aspiration in diagnosing and staging lung cancer. How many aspirates are needed? Am J Respir Crit Care Med 2002; 166:377-81.

12 Sharafkhaneh A, Baaklini W, Gorin AB, et al. Yield of transbronchial needle aspiration in diagnosis of mediastinal lesions. Chest 2003; 124:2131-5

13 Davenport RD. Rapid on-site evaluation of transbronchial aspirates. Chest 1998:98:59-61.

14 Herth FJ, Becker HD, Ernst A. Ultrasound-guided transbronchial needle aspiration. An experience in 242 patients. Chest 2003;123:604-7.

15 De Castro FR, Diaz Lopez F, Serdà GJ, et al. Relevance of training in transbronchial fineneedle aspiration technique. Chest 1997; 111:103-5.

16 Haponik EF, Cappellari JO, Chin R, et al. Education and experience improve transbronchial needle aspiration performance. Am J Respir Crit Care Med 1995;151:1998-2002.

17 Li-Han Hsu, Chia-Chuan Liu, Jen-Sheng Ko. Education and experience improve the performance of transbronchial needle aspiration. A learning curve at a cancer center. Chest 2004; 125:532-40.

18 Holty J-EC, Kuschner WG, Gould MK. Accuracy of transbronchial needle aspiration for mediastinal staging of non-small cell lung cancer: a meta-analysis. Thorax 2005;60:949-55.

19 Toloza EM, Harpole L, Detterbeck F, et al. Invasive staging of non-small cell lung cancer. A review of the current evidence. Chest 2003;123(1 Suppl):157-66S.

20 Pastis NJ, Nietert PJ, Silvestri GA. Variation in training for interventional pulmonary procedures among US pulmonary/critical care fellowships: a survey of fellowship directors. Chest 2005; 127:1614-21.

21 Ernst AE, Silvestri GA, Johnstone D. Interventional pulmonary procedures: guidelines from the American College of Chest Physicians. Chest 2003;123:1693-717. 
Orphan lung diseases in children

\section{Orphan lung diseases in childhood: still unadopted?}

\section{A Jaffé}

Despite recent initiatives, the UK is failing adequately to address the inequities in healthcare provision for children with rare lung disease

$M$ oney drives research-whether it is for profit by drug companies or for academic status by universities. It is therefore not surprising that little has been done in the past for patients with rare lung diseases, where there is little financial incentive for drug companies or the small population does not merit sufficient grant funding for adequately powered clinical studies. This problem is further compounded in children where research is perceived to be even more difficult. Over the recent years, largely due to extensive lobbying from independent patient support groups, there has been a concerted effort by the European Parliament and the USA government to address these inequities.

The French originally coined the term "orphan" disease, now defined as a disease with a prevalence of less than 5 in 10000 individuals, and they have been instrumental in addressing the many problems faced by patients suffering from these diseases. It is estimated that there are 7000 rare diseases affecting 27 million people in Europe and a further 27 million in North America. The adoption of recent laws such as the loi sur l'égalité des droits et des chances, la participation et la citoyenneté des personnes handicapées (law on equality of rights and opportunities, the participation and the citizenship of the handicapped) by the French Parliament makes specific reference to rare diseases. In addition, European Parliament legislation in 1999 on orphan drug development provides access to treatments for patients with rare diseases and encourages industry to develop new treatments by providing financial inducements. Similar legislation has been in place in the USA since the 1983 Orphan Drug Act. In the USA the Rare Disorders Act of 2002 formally established a statutory authorisation for the Office of Rare Disorders (ORD) at the National Institutes of Health (NIH), which had been in existence since 1993, and increased substantial investment into national collaborative research for patients with orphan lung diseases. This act has allowed the ORD to play an increasing role in governing the research agenda at NIH.

These recent political developments have largely been in response to lobbying by various independent patient organisations which have been instrumental in pushing rare diseases up the governments' agenda. The European Organisation for Rare Diseases (funded by the European Union) and Contact a Family (an independent UK charity) are patient driven alliances aimed at educating both the public and healthcare professionals and providing support for families. Individual charities such as the Cystic Fibrosis Trust and Lymphangioleiomyomatosis (LAM) Action, originally set up as family support networks, are examples of successful charities which set clinical standards, provide education and information and patient support, as well as driving research into a particular disease. ${ }^{1}$ A further example of how these alliances have affected political change is the development of the French National Plan which specifically praises the French Muscular Dystrophy Association for raising awareness (www.orpha.net/docs/PMR-GB.pdf).

The French National Plan for rare diseases (2005-8) represents an excellent framework for addressing the problems associated with rare lung diseases. Their objectives centre around the following strategic priorities:

- to increase knowledge of the epidemiology of the diseases;

- to recognise the specificity of these diseases;

- to develop information for patients, health professionals and the general public;

- to train health professionals in identifying rare diseases;

- to organise screening and access diagnostic tests;

- to improve access to treatment and inequality of patient care;
- to support orphan drug development;

- to respond to the specific needs of patients suffering from rare diseases; and

- to promote research and develop national and European partnerships.

So what implications do the above strategies have specifically for children with orphan lung disease? In recent years various surveillance methods have been employed to gather information on these diseases. One such approach is to gather information on a specific rare disease. A national survey conducted in the UK and Ireland on interstitial lung disease (ILD) in children ${ }^{2}$ subsequently led to the development of an ERS Taskforce Statement. ${ }^{3}$ A similar initiative for obliterative bronchiolitis is currently being carried out in the UK coordinated from Newcastle. The GISInstitut des Maladies Rares is currently sponsoring the establishment of a European Registry with the objective of collecting clinical data on people with congenital central hypoventilation syndrome. Initial work confined to France has provided important epidemiological data on the disease, ${ }^{4}$ and the result of case collection has led to a greater understanding of the genetic contribution to the disease. 5 One ambitious approach is that undertaken by the Children's Interstitial Lung Disease Research Network (ChILD) in the USA. The aim is to gather clinical cases to increase understanding of the pathophysiology, genetics and clinical phenotype of these conditions. It is envisaged that a consensus document will be produced on the diagnosis and evaluation of the young child with ILD. ChILD is funded by the American Thoracic Society through their Assembly Project Grants, and is part of the Rare Lung Disease Clinical Research Network which is being set up in Cincinatti Children's Hospital Medical Centre following an award of \$5.5 million from the NIH. In addition to the establishment of the clinical research network, parents of children with ILD have established a foundation (the ChILD Foundation). The ChILD Foundation website contains useful information on ILD and a discussion forum enabling the exchange of information between parents who often feel isolated.

Another approach to gathering information on rare disorders has been to use a monthly reporting system for a variety of diseases. The British Paediatric Surveillance Unit, established in 1986, has been a pioneer in developing reporting systems aimed at identifying the prevalence and incidence of rare childhood diseases. This model has been adopted throughout the world, and 
recently provided epidemiological data on children with non-CF bronchiectasis in New Zealand. ${ }^{6}$ The adult British Orphan Lung Disease project (BOLD), a British Thoracic Society initiative, is based on a similar monthly reporting system aimed at gathering information on rare adult lung diseases. At the beginning of 2005 the British Paediatric Orphan Lung Disease (BPOLD) registry was launched, modelled largely on BOLD but using a fully electronic reporting system. The aim of this registry is to gather cases of nine paediatric orphan lung diseases. Paediatricians with an interest in respiratory medicine are e-mailed monthly reminders to submit new cases or declare "nothing to report" to a web based repository. In addition to containing medical information on the specific orphan lung diseases, the website has a discussion forum allowing parents and families to exchange information. This project was made possible through funding from a charitable trust and the British Paediatric Respiratory Society. It is hoped that it will be a useful resource for future investigators wanting to carry out research into these specific diseases.

Clearly the internet has become important in raising awareness, gathering epidemiological data, and educating the professional and lay public. Again, the French have led the way. Orphanet is a multilingual internet based information server created in 1997 and aims to be the reference portal in Europe for access to all information on rare diseases. Orphanet UK, funded by the European Commission, is run by the North West Genetics Knowledge Park in Manchester and links in directly to Orphanet. Orphanet UK is collecting data related to rare diseases in the areas of laboratory diagnostics, specialised outpatient services, research projects, clinical trials, support groups, professional networks, and national registries. Another electronic initiative in the UK is the National Electronic Library of Health funded by the National Health System. The aim is to provide clinicians with access to the best current knowledge to support health care related decisions which will hopefully be integrated into future electronic patient records. An electronic specialist respiratory library was launched in 2004 and a library specific for rare diseases is currently under construction. Useful web links for rare diseases are listed in tables 1 and 2 .

It is clear from the above discussion that there is an increasing awareness of recognising the importance of rare lung diseases and various countries have instituted initiatives to address these problems. Despite some advances in the

Table 1 Web links for general rare diseases

\begin{tabular}{|c|c|c|}
\hline Website & Description & Address \\
\hline $\begin{array}{l}\text { National Electronic } \\
\text { Library for Health } \\
\text { Specialist Libraries }\end{array}$ & $\begin{array}{l}\text { NHS sponsored specialist } \\
\text { libraries primarily aimed at } \\
\text { professionals }\end{array}$ & $\begin{array}{l}\text { www.nhs.uk/rarediseases (in } \\
\text { development) http:// } \\
\text { libraries.nelh.nhs.uk/respiratory }\end{array}$ \\
\hline $\begin{array}{l}\text { GIS-Institut des } \\
\text { Maladies Rares }\end{array}$ & $\begin{array}{l}\text { French site for developing } \\
\text { research into rare diseases }\end{array}$ & www.institutmaladiesrares.net \\
\hline $\begin{array}{l}\text { International Network } \\
\text { of Paediatric } \\
\text { Surveillance Units }\end{array}$ & $\begin{array}{l}\text { International surveillance of rare } \\
\text { childhood diseases }\end{array}$ & www.inopsu.com \\
\hline Orphanet & $\begin{array}{l}\text { European reference portal } \\
\text { dedicated to information on rare } \\
\text { diseases and orphan drugs }\end{array}$ & www.orpha.net \\
\hline Orphanet UK & $\begin{array}{l}\text { UK site feeding directly into main } \\
\text { Orphanet }\end{array}$ & $\begin{array}{l}\text { www.orphanet.co.uk } \\
\text { (in development) }\end{array}$ \\
\hline $\begin{array}{l}\text { Office of Rare } \\
\text { Disorders }\end{array}$ & $\begin{array}{l}\text { US site providing information } \\
\text { about research, scientific } \\
\text { conferences, rare and genetic } \\
\text { diseases and a portal to } \\
\text { information on rare diseases }\end{array}$ & http://rarediseases.info.nih.gov/ \\
\hline $\begin{array}{l}\text { National Organisation } \\
\text { for Rare Disorders }\end{array}$ & $\begin{array}{l}\text { A USA voluntary health agency } \\
\text { containing databases on rare diseases } \\
\text { serving patients and their families }\end{array}$ & www.rarediseases.org \\
\hline Contact a Family & $\begin{array}{l}\text { Independent UK charity with } \\
\text { information on over } 2000 \text { disorders, } \\
\text { the majority of them rare disorders, } \\
\text { and a useful resource for families } \\
\text { and health practitioners }\end{array}$ & www.cafamily.org.uk \\
\hline $\begin{array}{l}\text { European Organisation } \\
\text { for Rare Diseases }\end{array}$ & $\begin{array}{l}\text { An alliance of rare disease patient } \\
\text { associations within Europe }\end{array}$ & www.eurordis.org \\
\hline
\end{tabular}

UK, there is an urgent need for a unified approach at a national level to address the inequity of healthcare provision which exists for patients with rare disorders. The Department of Health has hinted at the importance of addressing rare disorders in the National
Service Framework (NSF) for disabled children and young people with complex health needs. ${ }^{7}$ This NSF specifically highlights the need for health and local systems to plan for identifying and meeting the needs of children with low incidence and rare conditions. In

Table 2 Web links specifically for rare lung diseases

\begin{tabular}{|c|c|c|}
\hline Website & Description & Address \\
\hline $\begin{array}{l}\text { Congenital Central } \\
\text { Hypoventilation Syndrome }\end{array}$ & European registry & $\begin{array}{l}\text { www.cchsregistry.org (in } \\
\text { development) }\end{array}$ \\
\hline $\begin{array}{l}\text { Congenital Central } \\
\text { Hypoventilation Syndrome } \\
\text { Family Network }\end{array}$ & $\begin{array}{l}\text { US network aimed at supporting } \\
\text { families, promoting education } \\
\text { and research }\end{array}$ & www.cchsnetwork.org \\
\hline $\begin{array}{l}\text { British Paediatric Orphan } \\
\text { Lung Disease Registry }\end{array}$ & $\begin{array}{l}\text { Registry aimed at gathering cases } \\
\text { of rare childhood lung diseases. } \\
\text { Contains links to patient/family } \\
\text { discussion forum }\end{array}$ & www.bpold.co.uk \\
\hline $\begin{array}{l}\text { British Orphan Lung Disease } \\
\text { Registry }\end{array}$ & $\begin{array}{l}\text { Adult registry for rare lung } \\
\text { diseases }\end{array}$ & $\begin{array}{l}\text { www.brit-thoracic.org.uk/ } \\
\text { introduction_to_bold.html }\end{array}$ \\
\hline $\begin{array}{l}\text { Children's Interstitial Lung } \\
\text { Disease Foundation }\end{array}$ & $\begin{array}{l}\text { Charity supporting families with } \\
\text { interstitial lung disease. Contains } \\
\text { a patient/family discussion forum }\end{array}$ & www.childfoundation.info \\
\hline $\begin{array}{l}\text { Lymphangioleiomyomatosis } \\
\text { Action }\end{array}$ & $\begin{array}{l}\text { Contains information for patients } \\
\text { and doctors caring for patients } \\
\text { with LAM }\end{array}$ & www.lamaction.org \\
\hline $\begin{array}{l}\text { Groupe d'etudes et de } \\
\text { recherché sur les maladies } \\
\text { 'orphelines' pulmonaire }\end{array}$ & $\begin{array}{l}\text { French site dedicated to research } \\
\text { into orphan lung diseases }\end{array}$ & http://germop.univ-lyon 1.fr \\
\hline British Lung Foundation & $\begin{array}{l}\text { Information on a range of rare } \\
\text { lung disorders }\end{array}$ & www.lunguk.org \\
\hline
\end{tabular}

problems. Despite some advances in the

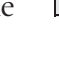


addition, the Genetics white paper published by the government in 2003 also addresses some of the issues of rare disorders, but only from a genetics perspective. ${ }^{8}$ However, there remains an urgent need for the government specifically to address the issues of rare diseases in the UK, similar to that outlined in the French National Plan. We in the UK may have been successful in winning the right to stage the Olympics, but when it comes to rare lung diseases it is the French who deserve the gold medal.

\section{ACKNOWLEDGEMENTS}

BPOLD is funded by the Cohen-Zimbler Family Trust and the British Paediatric Respiratory Society. I would like to thank Richard Lynn of BPSU, Diane Barnett of
Contact a Family, and Emma Gillaspy, Orphanet UK for their help in preparing this manuscript.

Thorax 2005;60:892-894.

doi: $10.1136 /$ thx.2005.050187

Correspondence to: $\operatorname{Dr}$ A Jaffé, Portex Respiratory Medicine Group, Great Ormond Street Hospital for Children NHS Trust and Institute of Child Health, Great Ormond Street, London WCIN 3JH, UK; a.jaffe@ich.ucl.ac.uk

Adam Jaffé is chairman of the British Paediatric Orphan Lung Disease Registry Committee

\section{REFERENCES}

1 Johnson SR, Whale Cl, Hubbard RB, et al. Survival and disease progression in UK patients with lymphangioleiomyomatosis. Thorax 2004:59:800-3

2 Dinwiddie R, Sharief N, Crawford O. Idiopathic interstitial pneumonitis in children: a nationa survey in the United Kingdom and Ireland. Pediatr Pulmonol 2002;34:23-9.

3 Clement A. Task force on chronic interstitial lung disease in immunocompetent children. Eur Respir J 2004;24:686-97.

4 Trang H, Dehan $M$, Beaufils $F$, et al. The French Congenital Central Hypoventilation Syndrome Registry: general data, phenotype, and genotype. Chest 2005:127:72-9.

5 Weese-Mayer DE, Berry-Kravis EM. Genetics of congenital central hypoventilation syndrome: lessons from a seemingly orphan disease. Am J Respir Crit Care Med 2004; 170:16-21.

6 Twiss J, Metcalfe R, Edwards E, et al. New Zealand national incidence of bronchiectasis "too high" for a developed country. Arch Dis Child 2005;90:737-40.

7 Department of Health. National Service Framework for Children, Young People and Maternity Services. Disabled children and young people and those with complex health needs. London: Department of Health, 2004

8 Department of Health. Our inheritance, our future. Realising the potential of genetics in the NHS. London: Department of Health, 2003.

\section{LUNG ALERT}

Treatment of advanced NSCLC: promising results with the FTase inhibitor lonafarnib

$\Delta$ Kim ES, Kies MS, Fosella FV, et al. Phase II study of the farnesyltransferase inhibitor lonafarnib with paclitaxel in patients with taxane-refractory/resistant non-small cell lung carcinoma. Cancer 2005; 104:561-9

$\mathrm{V}$

arious cell signalling and centromere proteins whose function is perturbed and/or upregulated in human tumours require the addition of a farnesyl pyrophosphate molecule for normal function. Farnesyl transferase (FTase) inhibitors block this step, reduce the function of these oncogenic proteins, and inhibit the growth of a variety of human tumour cell lines. FTase inhibitors are well tolerated, but previous monotherapy cancer trials have had disappointing outcomes. Further work on cancer cell lines has shown that FTase inhibitors act synergistically with cytotoxic drugs (particularly taxanes) and positively influence tumour resistance; combination trials have been proposed.

The authors studied the combination of the oral FTase inhibitor lonafarnib and paclitaxel in 33 patients with advanced stage IIIb/IV non-small cell lung cancer (NSCLC) who had progressive disease despite recent taxane based chemotherapy. Open label treatment consisted of 3 week cycles with continuous lonafarnib $100 \mathrm{mg}$ twice daily and paclitaxel $175 \mathrm{mg} / \mathrm{m}^{2}$ given on day 8 . The disease was evaluated following each cycle and treatment stopped if there was disease progression. This preliminary study was restricted to patients who had no cerebral metastases, had good performance status, no major co-morbidity, and no significant persistent toxicities from previous treatment.

Fourteen patients had a partial response or stable disease on trial therapy (which is impressive given that all patients had taxane resistant/refractory disease when enrolled). The treatment was well tolerated. These encouraging results have prompted the authors to begin a larger phase III trial (with carboplatin, paclitaxel and lonafarnib) for the first line treatment of patients with NSCLC.

Although the results reported here are preliminary and directly applicable to only a small subset of patients with NSCLC, it is hoped that FTase inhibitors will prove to be useful.

C Carlin

Clinical Research Fellow, Scottish Pulmonary Vascular Unit, Western Infirmary, Glasgow, UK ccarlin@tiscali.co.uk 